\title{
Modelagem Matemática dos Ventos para Aplicação em Sistemas Eólicos
}

\author{
Ayoanma C. de Azevedo* Erick F. da Costa Vandilberto P. Pinto \\ Curso de Engenharia Elétrica - Universidade Federal do Ceará - Campus Mucambinho Sobral - Rua \\ Estanislau Frota, S/N - Centro CEP: 62010-560 Sobral - Ceará \\ E-mail: ayoanma.c@hotmail.com erickfrotac@gmail.com vandilberto@yahoo.com.br
}

\section{RESUMO}

A geração de energia elétrica através de fontes renováveis é de suma importância na diversificação da matriz energética brasileira. Estas não produzem tantos poluentes, têm uma boa aceitação social e os incentivos do governo tornam o investimento atraente [1]. A geração eólica utiliza como energia primária o vento, que é gratuito, e a geografia brasileira dispõe de um imenso litoral com grande potencial eólico, tornando esta uma importante fonte de energia para o país. Neste trabalho será apresentada a modelagem matemática dos ventos com o objetivo de emular o comportamento dos ventos para aplicações em sistemas eólicos.

A representação do vento é caracterizada por duas grandezas variantes no tempo: velocidade e direção. Estes respondem a variações naturais, como rajadas e turbulências, e a variações sazonais [2]. A formulação da velocidade do vento pode ser representada pela soma de quatro componentes: velocidade média (ou base), rajada, rampa e ruído [3].

Eq. 1

$$
V_{\text {vento }}=V_{\text {base }}+V_{\text {rajada }}+V_{\text {rampa }}+V_{\text {ruído }}
$$

O vento base se trata da velocidade média do vento. A componente da rajada é representada por:

$$
V_{\text {rajada }}=\left\{\begin{array}{c}
0, \quad t<t_{\text {irajada }} \\
V_{\text {cos }}, \quad t_{\text {irajada }}<t<T_{\text {rajada }} \\
0, \quad t>t_{\text {irajada }}+T_{\text {rajada }}
\end{array}\right.
$$

Eq. 2

$$
V_{\text {cos }}=\left(\frac{R_{M A X}}{2}\right) *\left\{1-\cos 2 \pi\left[\left(\frac{t}{t_{\text {irajada }}}\right)-\left(\frac{t_{\text {irajada }}}{T_{\text {rajada }}}\right)\right]\right\}
$$

Onde: $T_{\text {rajada }}$ - período da rajada [s], $t_{\text {irajada }}$ - tempo de início da rajada [s], $R_{M A X}$ - valor máximo da rajada $[\mathrm{m} / \mathrm{s}]$.

A componente da velocidade em rampa, ascendente ou descendente pode ser matematicamente expressa por:

$$
V_{\text {rampa }}=\left\{\begin{array}{cc}
0, & t<t_{\text {irampa }} \\
V_{\text {ramp }}, & t_{\text {irampa }}<t<t_{\text {frampa }} \\
& 0, \quad t>t_{\text {frampa }}
\end{array}\right.
$$

Eq. 3

$$
V_{\text {ramp }}=R A M_{M A X} *\left[1-\frac{\left(t-t_{\text {frampa }}\right)}{\left(t_{\text {irampa }}-t_{\text {frampa }}\right)}\right]
$$

Onde: $R A M_{M A X}$ - valor máximo da rampa $[\mathrm{m} / \mathrm{s}], t_{\text {irampa }}$ - tempo de início da rampa [s], $t_{\text {frampa }}$ - tempo final da rampa [s].

A Eq. 3 é referente a uma rampa ascendente. Para uma rampa descendente basta que se inverta o sinal de $V_{\text {ramp }}$.

A componente denominada ruído que representa a parte randômica do sinal é dada por:

$$
V_{\text {ruido }}=2 \times \sum_{i=1}^{N}\left[S_{v}\left(\omega_{i}\right) \Delta \omega\right]^{\frac{1}{2}} \cos \left(\omega_{i} t+\phi_{i}\right)
$$

Eq. 5

$$
\omega_{i}=\left(i-\frac{1}{2}\right) \Delta \omega
$$


Eq.6

$$
S_{v}\left(\omega_{i}\right)=\frac{2 K_{N} F^{2}\left|\omega_{i}\right|}{\pi^{2}\left[1+\left(\frac{F \omega_{i}}{\mu \pi}\right)^{2}\right]^{\frac{4}{3}}}
$$

Onde: $\phi_{i}$ - Variável randômica com densidade de probabilidade uniforme de 0 a $2 \pi, \Delta \omega$ Variação da velocidade [rad/s], N - Números de termos considerados, $K_{N}$ - Coeficiente de arrasto da superfície, $\mathrm{F}$ - Escala de turbulência, $\mu$ - Velocidade principal do vento da altura de referência. Os valores das variáveis do ruído foram retirados de [3]. A Figura 1 mostra um vento base, um vento em rajada, uma rampa ascendente e um vento completo com as quatro componentes, respectivamente.

Os resultados de simulações apresentados demonstram uma boa representação do comportamento típico dos ventos que serão aplicados como sinal de entrada na simulação de um sistema de geração eólica a fim de testar estratégias de controle.
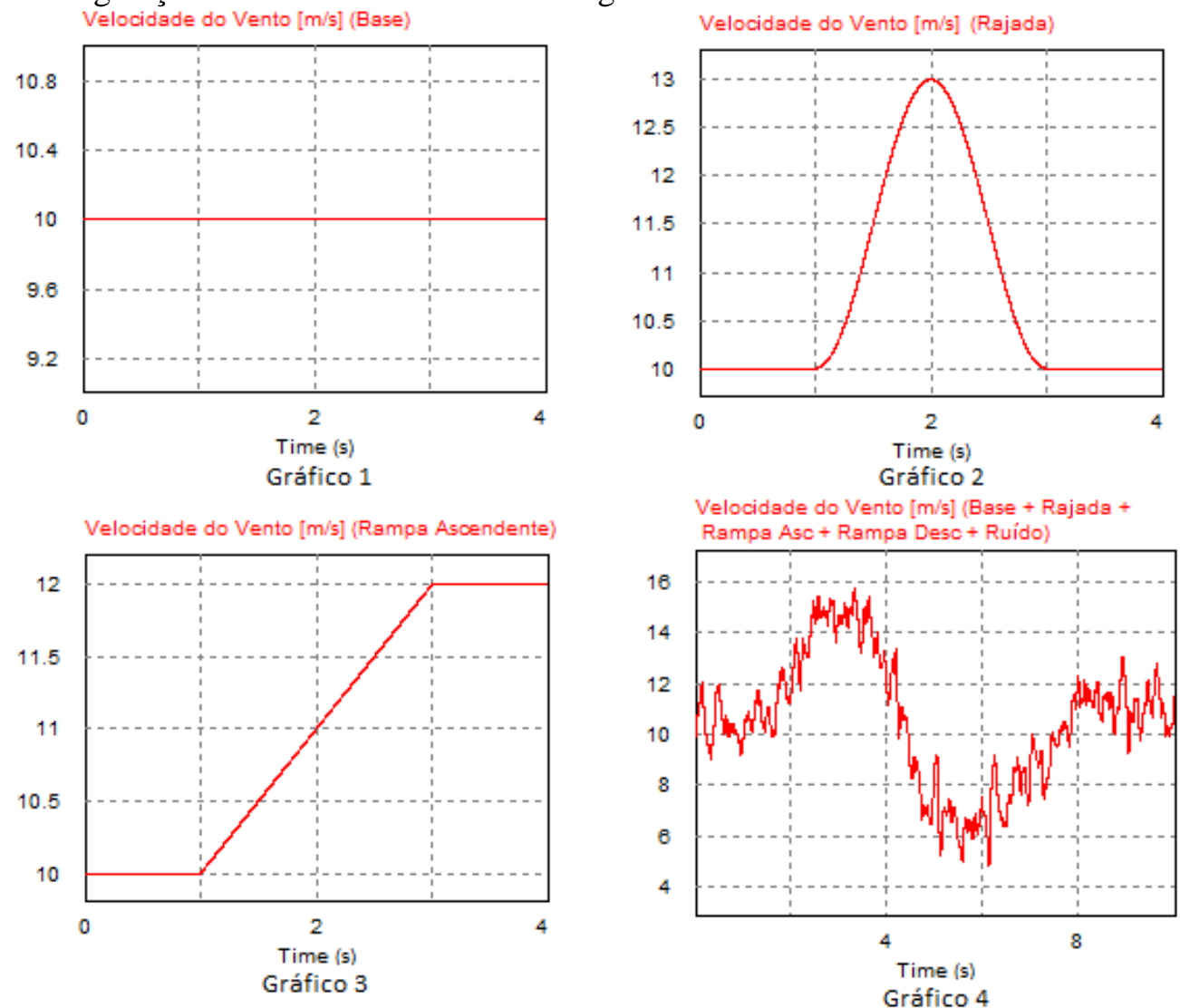

Figura 1 - Gráficos de Simulação dos Ventos.

Palavras-chave: Modelagem Matemática, Ventos, Geração Eólica.

\section{Referências Bibliográficas}

[1] J. P. Costa, "Contribuição ao Estudo do Gerador de Indução Duplamente Alimentado: Operação Durante Distúrbios na Rede Elétrica", Tese de Doutorado, Universidade Federal de Santa Maria, 2010.

[2] K. F. Silva, "Controle e Integração de Centrais Eólicas à Rede Elétrica com Geradores de Indução Duplamente Alimentados", Tese de Doutorado, Universidade de São Paulo, 2006.

[3] P. M. Anderson and A. Bose, "Stability Simulation of Wind Turbine Systems", IEEE Transactions on Power Apparatus and Systems, Vol. PAS-102, No. 12, 1983. 